\title{
Computer Simulation of Building Energy Consumption and Building Energy Efficiency
}

\author{
Zhao Lei \\ Architectural Engineering \\ Xinxiang University
}

\author{
Song Jingying \\ Architectural Engineering \\ Xinxiang University
}

\begin{abstract}
Computer simulation of building energy consumption is one of important assisted tools in the field of energy efficiency, architects can easily design process at any stage of the design of energy-saving evaluation by computer simulation, or test can predict the future or existing Building energy consumption, diagnostic analysis of building thermal process, so as to optimize the building design to minimize energy consumption to provide an accurate basis.
\end{abstract}

Keywords-uilding energy efficiency, Building energy simulation computer technology, Architectural design

\section{INTRODUCTION}

All manuscripts must be in English. These guidelines include complete descriptions of the fonts, spacing, and related information for producing your proceedings manuscripts. Please follow them and if you have any questions, direct them to the production editor in charge of your proceedings at Conference Publishing Services (CPS): Phone +1 (714) 821-8380 or Fax +1 (714) 761-1784.

Since 90 years the 20th century, China began the implementation of building energy conservation, residential building energy efficiency has made some achievements, but should also summarize results of China's building energy consumption clearly see the gap with the developed countries, the objective of energy conservation work facts, and the huge energy saving potential. This requires building energy efficiency into account as soon as possible on a variety of energy-saving measures to all aspects of innovation as the basis, actively practice a variety of innovative technologies and promoting energy saving in building forward.

Building energy efficiency is the use of the building and construction process, the rational use and effective use of energy in order to meet the same needs or conditions to achieve the same purpose as much as possible to reduce energy consumption. Building energy consumption includes building energy consumption (materials, components and construction of energy production) and the construction process of the daily energy use (heating, lighting and appliances, etc.). The computer simulation technology is for energy saving building design and development.

\section{What Is A COMPUTER SIMULATION OF BUILDING ENERGY CONSUMPTION}

Building energy efficiency program planning must be from construction, construction equipment, system design begins. Different architectural style, different materials, different building equipment systems can be combined into many programs, from the many programs to select the most energy-efficient solutions, energy consumption must be estimated for each program, which is the computer building energy simulation technology.

Computer simulation of building energy consumption is one of important assisted tools in the field of energy efficiency. architects can easily design process at any stage of the design of energy-saving evaluation by computer simulation, or test can predict the future or existing buildings energy consumption, diagnostic analysis of building thermal process, so as to optimize the building design, to minimize energy consumption to provide an accurate basis. Just type in the program model of the architect, you can complete in design software, thermal performance, natural light, artificial lighting, sunlight, and economic analysis and understanding the impact of construction on the environment. These results can help the architect at the design stage compared the advantages and disadvantages of different options to make more energy-efficient choices can be completed in the software design of the thermal performance, natural light, artificial lighting, sunlight, and the economy analysis and understanding of the environmental impact of buildings. In recent years, with the large-scale application and popularization of computer, computer-based simulation software applications are constantly updated with the development of services for promoting green building and sustainable development an important force in the industry.

Computer simulation technology for the energy building energy simulation software for architects in building design and development. Use the software architect can easily design process at any stage of the design of energy-saving assessments. Architectural simulation software can be broadly classified into two categories, for the building design phase of building energy simulation software and energy efficiency standards for audit based on the consistency of evaluation software. Many European countries have developed their own building energy simulation software, play in the actual use of a larger economic and social benefits. Domestic and foreign applications and analysis of building thermal environment simulation software more, which is more popular and authority are: DOE-2 software, RNSYS software, ESP-r software, Climate Surface software, and FLUENT software. 


\section{DOMESTIC AND INTERNATIONAL COMPUTER BuILDing ENERgy Simulation TECHNOLOGy Status}

\section{A. Foreign application of computer building energy assessment}

Many foreign countries as early as 70 years in the 20th century began to apply computer technology to the building's energy assessments, and this made a lot of research, practical work, the most representative of the United States. The United States is to carry out Building Energy Research one of the earliest computer technology application in building energy saving and most robust. By the Lawrence Berkeley National Laboratory study team developed the DOE-2, more than 40 countries around the world for energy analysis of buildings, energy-saving standards, China's "hot summer and cold winter region residential building energy efficiency design standards "clearly provide for the DOE-2 software as a comprehensive energy conservation design of energysaving computing performance tools. [2] Western Europe, Northern Europe and North America in the world, development of more advanced simulation technology, simulation software in these areas, the promotion and application in many countries has reached a more mature level.

\section{B. The domestic computer building energy simulation technology}

Of the mid-70s from the 20th century began the computer simulation of building energy consumption in foreign countries and the development side, a lot of scientific and technical staff made a lot of work. Since we have 80 theoretical research, software development and engineering side to make unremitting efforts to reduce the technology gap with developed countries, has made some progress. Initially established in the software development of software in China series. DeST has now developed to improve the building energy simulation software portfolio, including analysis and optimization of energy consumption for residential design DeST-h, for residential energy assessment DeST-e, for large public buildings with air-conditioning system design optimization analysis of DeST -c, as well as large public building energy consumption for the assessment DeST-ce four versions. [1] has completed ten million square meters of building energy simulation analysis, including the National Grand Theater, Beijing Capital International Airport expansion, the national main stadium and other major projects in dozens of countries, China has started building energy efficiency design work. [5] has some applications in engineering theory and heating load calculation procedures, the cooling load calculation, building envelope thermal performance, thermal resistance and building the economy and regulate the development of energy-saving measures, solar energy and other parties which have made the problem larger progress.

However, our late start, the function of the software has yet to be strengthened types remains to be improved, the software update speed to be improved. State efforts to support the development of simulation software must also be further strengthened.

\section{COMPUTER BUILDING ENERGY SimUlation TECHNOLOGY}

\section{A. building energy simulation computer generated significant}

Building energy analysis is not a simple numerical calculation, the building must be integrated with complex situations that may arise in detail the building energy simulation analysis. Built environment is outdoor climate conditions, the indoor heat source heating variety of indoor and outdoor air conditions and the status of the decision. [6] Building environmental control system health status of the built environment must also change with the ongoing necessary adjustments to achieve the comfort and meet the other requirements of the built environment. As construction environmental change is determined by many factors, a complex process, so only the method by computer simulation can be effectively predicted construction environment in the absence of environmental control system and the existing environmental control system when the situation that may arise when, for example, room temperature humidity over time, when the heating energy consumption by air conditioning systems, and building energy consumption required for environmental control throughout the year. Through building energy simulation analysis technology, enables designers to better handle the building envelope energy efficiency, energy conservation and construction equipment, individual equipment and system energy saving, energy saving and indoor environment quality and the relationship between saving and energy saving to design a better, more reasonable energy-saving buildings.

Energy simulation is important because you can build the building before the building thermal performance provides valuable information to help designers improve the design; or evaluate design performance in energy consumption, testing the effect of energy saving measures to reduce design risk, avoid unnecessary waste. We only use a reasonable method for simulation of energy consumption, control the power consumption of the building, good energy-saving building design, choose the right energy-saving equipment, energy-efficient heating and air conditioning design and control system in order to really achieve energy savings .

\section{B. Computer simulation of building energy consumption characteristics}

\section{1) changed hands ease of use}

Easy software has a good nature, mode of operation is simple and clear, detailed tips and help, input and output a complete and easy to operate.

\section{2) The integrity of the data read}

Can reflect the whole building hourly load changes. And can accurately analyze the data of different types of parameters.

3 ) software, an extension of

Building energy facilities on the rise, the continuous development of energy-saving technologies, energy 
consumption in all aspects of the system can be continuously expanded to meet the various periods and regions of different characteristics.

\section{Architectural Design and integration of building energy simulation computer}

Architectural design and computer simulation of building energy consumption shall not be treated with if, the data will be detected is not ideal, or even bias or error. Computer calculation of building energy consumption in the whole process of architectural design is very important to use the location, such as the construction phase in the construction program began to quantitative calculation and evaluation of building energy consumption, building energy consumption calculation also lost due to the design guide and Evaluation of nature can not achieve true energy-saving purposes, but will result in large areas of energy waste.

Niles Larsson in GBC2000 "green building a move towards sustainable" to Moving TowardsSustainability with Green Building) mentioned in the article the integration of the architectural design process, and gives the framework for energy efficient building design process ( as shown in Figure 4-1). [3]

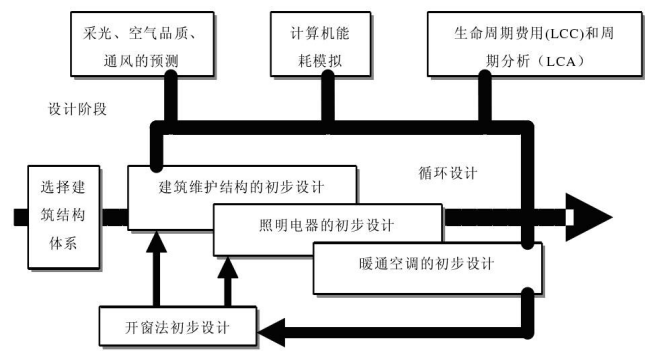

Figure 1. The position of the Computer energy simulation in building design

From the figure, the entire design process is a continuous cycle which the two parts through the exchange of information and feedback. First of all, emphasized the importance of computer simulation system can choose a variety of programs to test and evaluation, with evaluation of optimization program, which aims to further improve the program; after designers and architects through the communication and coordination, further improvement program.

From theory of Niles Larsson, we see the continuous cycle of information and feedback, but because of the design process of architectural design is a process of gradual and continuous feedback, every stage of the need to address different issues, each stage has been known and unknown conditions is not the same, with the design of the continuous deepening of the results of the previous stage will be the follow-up phase of the known conditions (as shown in Figure 3-2). At each stage, designers need to constantly modify the design to get the best design results. Established between the various stages through the level of the specific relationship between the different design stages can be combined into an organic whole design process, which covers the entire building "life cycle" of the design process. [1] Therefore, in addition to the necessary feedback and a loop somehow, every stage needs to have their information exchange, enabling the designer at every stage to revise and improve the design of targeted programs, travel patterns layer by layer optimized design to improve the effectiveness of building energy efficiency.

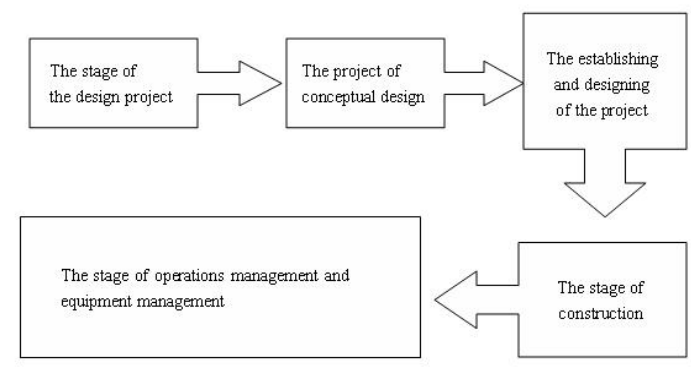

Figure 2. The general design process of architectural design

Thus, should the design process in architectural design, each of which is the calculation of building energy simulation computer, trip computer simulation of layered phases (as shown in Figure 3-3).

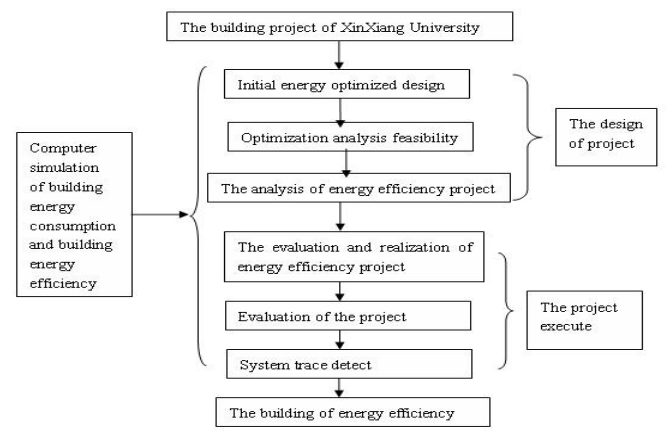

Figure 3. The applying of computer building energy simulation system

For example, coastal residential buildings, for example, computer building energy simulation system into every aspect of the design to reflect the optimum design through building energy consumption situation will greatly improve the energy consumption in the analog system is not applied to the design process Energy saving effect.

Summer cooling energy consumption compared two groups of models such as the summer cooling energy consumption of (Table I). Optimized design, the air conditioning energy consumption ratio reflects the thermal state of the existing residential down $67.8 \%$ of the initial model.

TABLE I. COOLING ENERGY CONSUMPTION COMPARED

\begin{tabular}{|l|l|l|}
\hline \multicolumn{1}{|c|}{ Project } & \multicolumn{1}{|c|}{ Not optimized } & optimized \\
\hline $\begin{array}{l}\text { Annual total cooling } \\
\text { load index }(\mathrm{kW} \cdot \mathrm{h} / \\
\mathrm{m} 2)\end{array}$ & 152.34 & 57.32 \\
\hline $\begin{array}{l}\text { Air conditioning energy } \\
\text { efficiency }\end{array}$ & 2.3 & 2.74 \\
\hline $\begin{array}{l}\text { Air-conditioning on } \\
\text { power }\end{array}$ & 68.41 & 20.65 \\
\hline
\end{tabular}




\begin{tabular}{|l|l|l|}
\hline consumption(kW $\bullet$ Mn2) & & \\
\hline $\begin{array}{l}\text { Air-conditioning energy } \\
\text { saving rate }\end{array}$ & 0 & $69.1 \%$ \\
\hline
\end{tabular}

From this, the computer building energy simulation and building design should be truly rational combination of different processes, and implementation of a suitable location, layered, layer by layer information feedback and optimization, it may be true of building energy efficiency Purposes.

\section{CONCLUSION}

Building energy simulation in building energy efficiency is an important technology for building a real sense of the crucial role that energy conservation. With the strengthening of building energy management, local hourly weather database development, simulation software continues to improve, building energy simulation technology will be increasingly widely used, and building energy conservation, environmental protection and sustainable development will undoubtedly have far-reaching Effects.

\section{ACKNOWLEDGMENT}

This work has been supported by a donation from the teacher research fund of China Earthquake Administration (No. 20090113).

\section{REFERENCES}

[1] Hu Yumei. Compute simulation and analysis of energy consumption of energy-saving design,Hebei University of Technology[D],2007.03

[2] Ding zhuoping, Jin-Song Bao, Ding exercise. Research of Software Development for Buildings Energy-efficiency Assessment System, Journal of Hunan University (Natural Science)[J], April 2003, Vol 30, No. 2: 83

[3] Nils Larsson. Green building Challenge 2000 Building and Environment 42(2002)113-117

[4] Zhang Cheng. The simulation analysis of building for the building design process,Xi'an university of architecture and technology [D], 2003

[5] Jiang Yi. of building energy consumption and enabling state saving means [EB/OL],http://www.sketchup.com.cn/

[6] Huang junpeng, Li Zhengrong. Building energy efficiency computer evaluation systems, Heating and air-conditioning [J], 2004, 34 (11) 